\title{
IMF and Lower Thermospheric Currents and Motions: A Review
}

\author{
Sadami Matsushita \\ High Altitude Observatory of NCAR, Boulder, \\ Colorado 80307, U.S.A.
}

(Accepted June 10, 1978)

\begin{abstract}
Effects of the interplanetary magnetic field (IMF), particularly its polarity, on the lower thermosphere are briefly reviewed. A fairly well-known indirect correlation is that both long-lasting southward IMF and the boundary between eastward and westward fields often cause magnetospheric disturbances which produce storm related thermospheric variations. A direct correlation is that the IMF westward (or eastward) component produces clockwise (or counterclockwise) circular electric currents in the lower thermosphere over the polar region. Computer simulation studies of a possible mechanism of this effect are presented. IMF effects on the change of the magnetospheric configurations without any appreciable thermospheric variation are also included, and suggestions for future investigations are provided.
\end{abstract}

\section{Introduction}

Concerning the effects of the interplanetary magnetic field (IMF) and its polarity (IMFP) on the geomagnetic field, particularly in high latitudes, numerous papers and review articles have recently been published (e.g. BURCH, 1974; NisHIDA, 1975; Feldstein, 1976; Fairfield, 1977). The IMF is represented by its magnitude $B$ and direction angles $\theta$ and $\phi$, and more commonly by three rectangular components $\left(B_{x}, B_{y}\right.$, and $\left.B_{z}\right)$ in a sun-earth coordinate system. Here, $(x, y$, and $z)$ indicate (sunward, eastward, and northward), respectively, although the exact directions of $y$ and $z$ components depend on the adopted sun-earth coordinate system, such as geocentric solar magnetospheric (GSM), ecliptic (GSE), and equatorial (GSEQ) coordinates (Russell and MCPherron, 1973). The GSE system has most frequently been used, but GSM is best for the discussion of IMF effects in all seasons. To indicate the IMF sector structure or the IMFP, the nomenclature TOWARD the sun $\left(B_{x}\right.$, usually associated with a $-B_{y}$ component; negative polarity) or AWAY from the sun ( $-B_{x}$, usually associated with a $B_{y}$ component; positive polarity) has often been used. Although the azimuthal westward $\left(-B_{y}\right)$ or eastward $\left(B_{y}\right)$ component is probably more appropriate for physical interpretations of high-latitude responses, the terms 'toward' and 'away' are also used in the present report for simplicity and for convenience of discussion of thermospheric responses.

As a common and customary practice in the past, the effects caused by $B_{z}$ and those by the sector structure have been discussed separately. Although it would 
probably be more relevant to discuss the IMF effects in the $y-z$ plane (e.g. FrirsChristensen and Wilhuelm, 1975) or those in all three components, the customary separation is adopted in the present review for convenience when introducing others' studies. Discussions of $B_{z}$ effects are presented in section 2, and those of sector influence are given in section 3. A new result of IMFP effects on lower thermospheric currents in high latitudes and computer simulation studies of a possible mechanism of the effects are also discussed in section 3. Concluding remarks and necessary future investigations are presented in section 4. IMF effects on various other phenomena, such as cosmic rays and Forbush decreases (Winkler and Bedijn, 1976; Ely, 1977; LockWood and Webber, 1977), solar wind speeds (Gosling et al., 1976), geomagnetic pulsations (Russell and Fleming, 1976; Webb and Orr, 1976; Arthur and McPherron, 1977), low-altitude electric fields (ReIter, 1977), and weather and climate (Wilcox, 1977; LARSEN and Kelley, 1977), are interesting subjects to discuss, but they are beyond the scope of the present review.

\section{2. $B_{z}$ Effects}

A southward IMF $\left(-B_{z}\right)$ which lasts longer than three hours usually causes substorm occurrence, probably due to the so-called field-reconnection process, although substorms can occur during periods of the northward IMF (see KAMIDE and MAtsushita, 1978 and references therein for a unified view of substorm occurrence). Good correlations among $-B_{z}$, geomagnetic variation fields at various stations, $E s-q$ disappearance at Huancayo (geomagnetic $-0.6^{\circ}, 354.3^{\circ} \mathrm{E}$; dip lat. $1.0^{\circ}$ ), the $E$ region east-west electron drifts over Jicamarca (geomagnetic $-0.6^{\circ}, 352.8^{\circ} \mathrm{E}$; dip lat. $0.5^{\circ}$ ) during disturbed periods were presented by MATSUSHITA and BALSLEY (1972, 1973). Since then, several Indian colleagues conducted similar studies, as reviewed by Matsushita (1977). Most of the days examined by them were geomagnetically disturbed. Caution is necessary, accordingly, in judging whether these equatorial ionospheric variations are directly produced by the IMF changes (particularly $-B_{z}$ ) or whether these variations are simply due to common storm effects. Although further data examinations are needed, the equatorial and low latitude ionospheric variations reported by them seem to be common ionospheric disturbances caused by geomagnetic storms or magnetospheric substorms probably triggered by $-B_{z}$, instead of direct production caused by the IMF changes.

Special electric current systems in the lower thermospheric region associated with $\pm B_{z}$ have been suggested by a few scientists, such as DP2 current caused by $-B_{z}$ (Nishida, 1968) and DP3 by $+B_{z}$ (IWASAKI, 1971). However, MAEZAWA (1976) presented different patterns of current systems caused by $\pm B_{z}$, and KuZNETsov and Troshichev (1977) used the name DP4 for the current due to the sector structure suggested by SvalgaARD (1973). Since those various current systems are complicated and depend on a proper zero level assumption, they require careful reexamination before such numbered nomenclature is adopted. A current system which is clearly associated with the IMFP is discussed in section 3. 
As for the relation between the IMF and thermospheric currents and motions, the thermospheric response to a substorm caused by $-B_{z}$ is an important subject to discuss (e.g. Rishbeth, 1975; Testud et al., 1975; Comfort et al., 1976; Roble and Rees, 1977). For example, a dynamo action by the middle and low latitude neutral wind caused by Joule heating in the polar cap and the auroral region is plausible (Matsushita, 1975a). Equatorward thermospheric motions in response to auroral region storm activity, as discussed by Richmond and MAtsushita (1975, see Figs. 3 and 4 therein), may produce electric currents and fields in middle and low latitudes.

\section{3. $B_{x, y}$ (Sector) Effects}

Wilcox and Ness (1965) first reported that geomagnetic activity increases when the earth crosses IMF sector boundaries. Since then, numerous scientists, most recently Campbell (1976) and Rangarajan (1977), confirmed this effect. Also, an increase of the radio wave absorption in the $D$ region during sector boundary passages was reported by Schlegel et al. (1977). Sector effects on the annual and diurnal variations of geomagnetic activity have recently been discussed by BERTHELIER (1976) and SvalgaARd (1976). For example, the activity peaks around April (or October) for toward (or away) polarity. Matsushita (1977) reviewed sector effects on geomagnetic variations in low and middle latitudes, and suggested magnetospheric configuration changes due to the sectors, without any appreciable thermospheric variations. Matsushita $(1975 b, 1977)$ also discussed IMFP effects on the $S q$ current system and reviewed others' work on this subject, while RAO and ArorA (1977) reported IMFP effects on $\mathrm{L}$, which require careful reexamination.

Sector effects on the polar cap geomagnetic fields, sometimes indicated as the "Mansurov-Svalgaard Effects", have fairly well been established (e.g. FAIRFIELD, 1977). Namely, in the northern hemisphere, the toward (or away) IMF sector structure correlates with positive (or negative) deviations of the geomagnetic downward component $Z$ at stations near $85^{\circ}$ invariant latitude (such as Thule) and with negative (or positive) deviations of the horizontal component $H$ at stations near $80^{\circ}$ invariant latitude (such as Godhavn). In the southern hemisphere, the same story holds for $Z$ but the sign reverses for $H$. The early analyses were done by visual judgement of the geomagnetic variations (e.g. SvalgaArd, 1972), but CAmpbell and Matsushita (1973) and CAMPBELL (1976) examined the relation objectively by an automated computer technique and concluded that a fairly good correlation can be obtained mainly in local summer.

To explain this correlation, schematic circular electric currents around the polar cap were postulated by BERTHELIER (1972) and SvalgaARD (1973), taking into consideration a theoretical suggestion given by JøRGENSEN et al. (1972), while a shift of magnetospheric convection was suggested by HEPPNER $(1972,1973)$ and differential rotations of the magnetospheric plasma were presented by Volland (1975a, b) on the basis of Heppner's observations. To facilitate discussion of the physical mechanism involved in the interaction, more detailed studies of IMFP effects were required. 
Fris-Christensen and Wilhjelm (1975) examined polar cap currents for different directions of IMF in the $y-z$ plane, while MATsushit a et al. (1973) obtained equivalent overhead current systems in high latitudes corresponding to toward and away sectors (see Fig. 1) by the technique of spherical harmonic analysis of 2.5 min digitized geomagnetic data from 40 stations. The $S q^{p}$ current systems at the right of Fig. 1 correspond to Heppner's schematic current patterns, but the $S q^{p}$ distortion is asym-

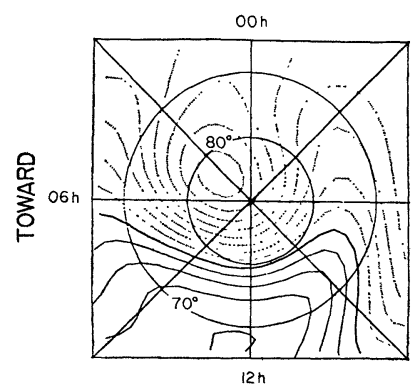

MAY \& JUNE 1965
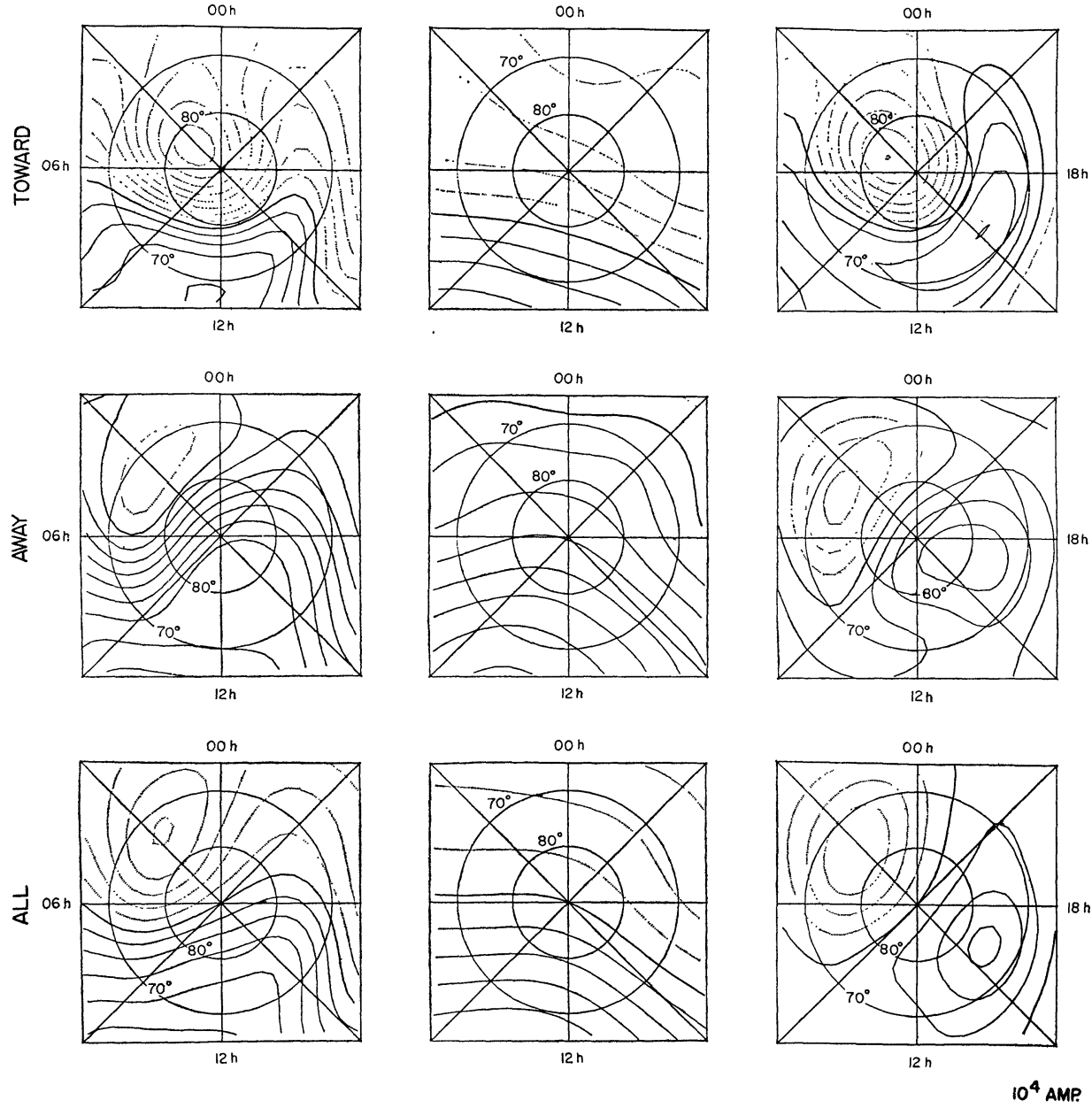

Fig. 1. Equivalent overhead current systems in the northern polar region on quiet days during May and June of 1965 corresponding to toward (top) and away (middle) sectors and all average (bottom). The left diagrams are current systems obtained from all 40 geomagnetic stations $\left(S q=S q^{0}+S q^{p}\right)$, the middle three are current systems extrapolated from values at $60^{\circ} \mathrm{N}\left(S q^{\circ}\right)$, and the right diagrams are differences of the two $\left(S q^{p}\right)$, in geomagnetic latitudes and time. The current intensity between two consecutive lines is $10^{4} \mathrm{amp}$, and solid and dotted lines indicate counterclockwise and clockwise currents, respectively (MATsushita et al., 1973). 


\section{QUIET MAY \& JUNE 1965 DISTURBED}
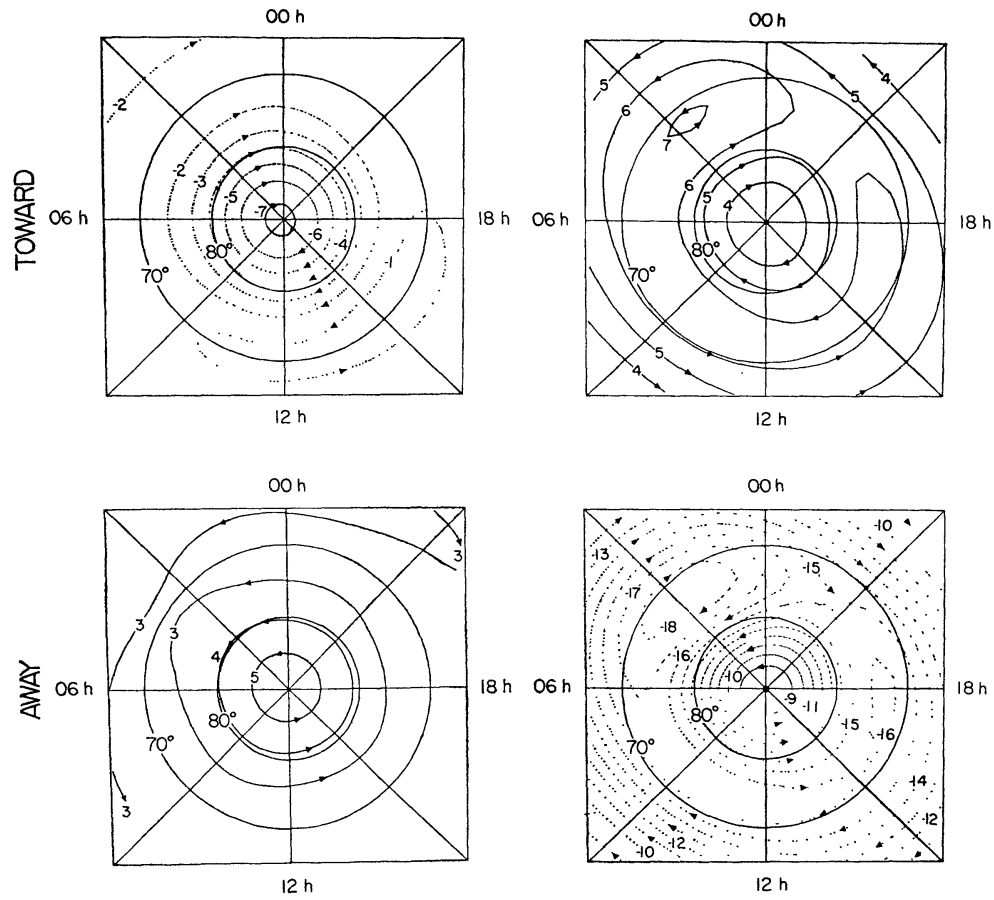

DIFFERENCES

Fig. 2. Difference current systems from all-average currents on quiet (left) and disturbed (right) days corresponding to toward (top) and away (bottom) sectors with a contour interval of $10^{4} \mathrm{amp}$ for quiet and $3 \times 10^{4} \mathrm{amp}$ for disturbed days.

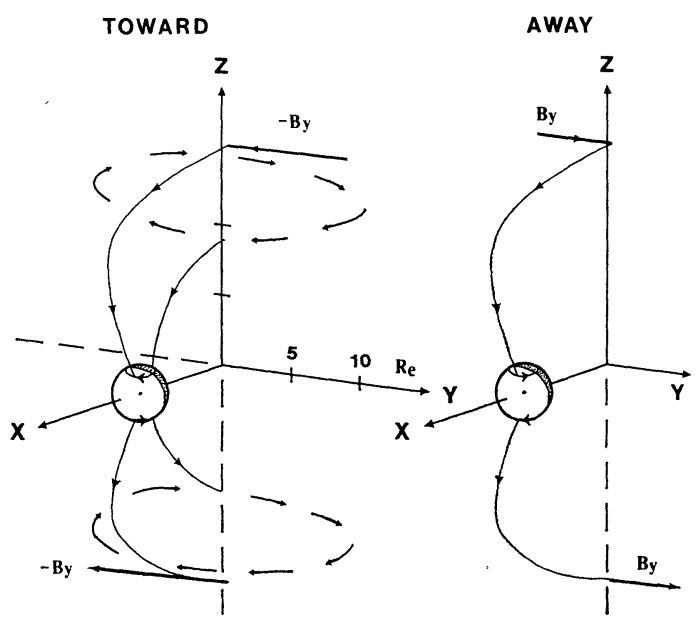

Fig. 3. Schematic explanation of plasma convection due to magnetic stresses of $\pm B_{y}$ on the northern and southern polar magnetospheric field lines. 
metric between the northern and southern hemispheres. Accordingly, a simple shift of magnetospheric convection in the magnetospheric equatorial plane is not suitable to explain the $S q^{p}$ distortion caused by the IMFP.

To lead to a reasonable explanation of IMFP effects, the average $S q$ current system (bottom left in Fig. 1) was subtracted from the $S q$ current system corresponding to toward or away (top or middle left diagram in Fig. 1); the differences are shown in the left of Fig. 2. The right two diagrams are differences of the current systems for disturbed days during May and June of 1965, and have been obtained by the same procedure as for the quiet days. Although the circular current intensities shown in Fig. 2 are different for the two sectors, they may be approximately equal in a general case. These circular currents may replace the schematic ones postulated by Berthelier (1972) and Svalgaard (1973). In other words, the shift of the equivalent external $S q^{p}$ current system with IMF sector changes (see Fig. 1) may be mainly caused by a circular electric current belt with about $3 \times 10^{4} \mathrm{amp}$ total current

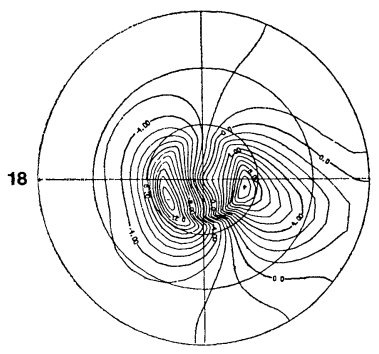

$1 \mathrm{kr}$

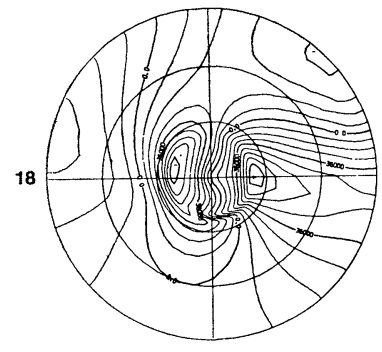

$9 \cdot 10^{3} \mathrm{~A}$

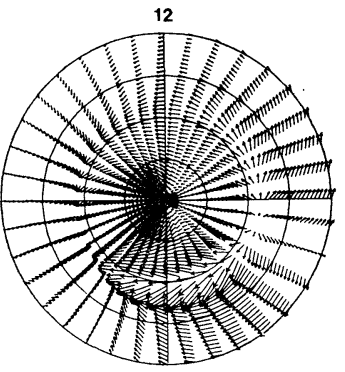

$10 \mathrm{mV} / \mathrm{m}$

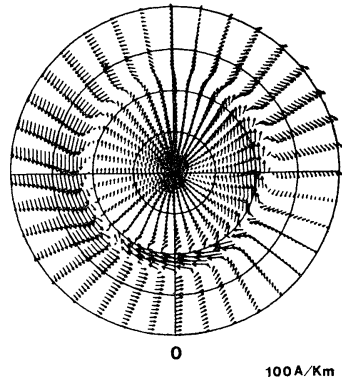

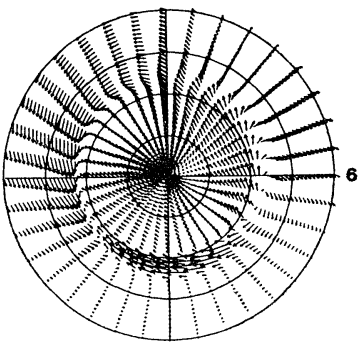

$130 \mathrm{~A} / \mathrm{Km}$

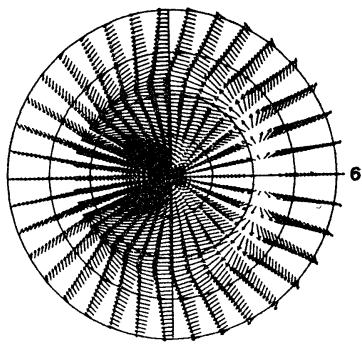

$50 \mathrm{~A} / \mathrm{Km}$

Fig. 4. Computer simulation of toward sector effect on the northern polar region for a summer quiet day, produced by field-aligned electric currents. Clockwise from top left: equipotential contours of the electric field with a contour interval of $1 \mathrm{kV}$; vector distribution of the electric field; real ionospheric current vectors; ionospheric current vectors equivalent to the magnetic field due to field-aligned currents; equivalent ionospheric current vectors (namely, difference between top right and bottom right diagrams); and equivalent overhead current system with a contour interval of $9 \times 10^{3} \mathrm{amp}$ (compare with top right diagram in Fig. 1). The left two diagrams show the northern hemisphere latitude circles with every $30^{\circ}$, while the four other vector diagrams are for the region from $50^{\circ} \mathrm{N}$ to the north pole. Note that the direction of the noon-midnight meridian is opposite to that in Fig. 1. 
for quiet days and about $10^{5}$ amp for disturbed days in summer at $75^{\circ}-85^{\circ}$ latitude. The current direction is clockwise (or counterclockwise) corresponding to the toward (or away) IMF, when it is viewed from above the pole at each polar cap. Here, toward (or away) is associated with the azimuthal westward (or eastward) IMF component, as explained in section 1. It must be noted that the current direction of the same IMF azimuthal component is reversed at the northern and the southern polar caps, when the circular currents in the two polar caps are viewed from the equatorial plane.

The formation of these circular electric currents in the lower thermosphere can be explained by electric fields associated with the oppositely-moving plasma convective motions in the northern and the southern polar magnetospheric regions due to magnetic stresses of the IMF azimuthal component on the magnetic field lines of the polar magnetosphere to which they are connected (AtKInson, 1975), as shown in Fig. 3. This mechanism can be demonstrated by a computer simulation technique of field-aligned electric currents, which has recently been developed by KAMIDE and Matsushita (1979). The essential points of the method are to obtain the electric fields and currents in the global ionosphere produced by the field-aligned currents, which change largely due to the conductivity distributions in high latitudes, assuming: 1) several divided regions of the global earth, such as the polar cap, auroral zones, and middle-low latitudes, where the boundaries of these regions vary depending upon magnetic conditions (for example, the night-side auroral zone has been divided into four; $70^{\circ}-65^{\circ}$ and $65^{\circ}-60^{\circ}$ latitudes before and after midnight for a typical substorm), 2) exponentially distributed anisotropic electric conductivities for each zone with a continuous change at the boundaries of the regions, and 3 ) exponentially distributed upward and downward field-aligned electric current intensities in the auroral regions (and also the polar cap for IMFP effects), based on our current knowledge of the auroral phenomena and geomagnetic variations as well as satellite measurements of field-aligned currents. Actual computer-plotted diagrams which can be obtained by this method are (1) equi-potential contours of the electric fields, (2) vector distributions of the electric fields and currents, and (3) electric current patterns equivalent to the magnetic field effect produced by the field-aligned and real ionospheric currents. An example is shown in Fig. 4. One of the merits of this simulation method is that the three dimensional current system can be estimated from the equivalent current system obtained from ground-based classic geomagnetic data.

As shown in Fig. 5, downward (or upward) electric currents with about $6 \times 10^{5}$ amp in total over the polar region are satisfactory for explaining the toward (or away) sector effect during a quiet summer. An approximately tripled intensity of the total current is required to simulate the effect during a substorm. Detailed discussions are given by MAtsushita and KAMIDE (1980), and an essential point here is that the required amount and configuration of field-aligned currents which are associated with the polar magnetospheric plasma convection are very plausible. In other words, these simulations provide a physical explanation for the circular elec- 

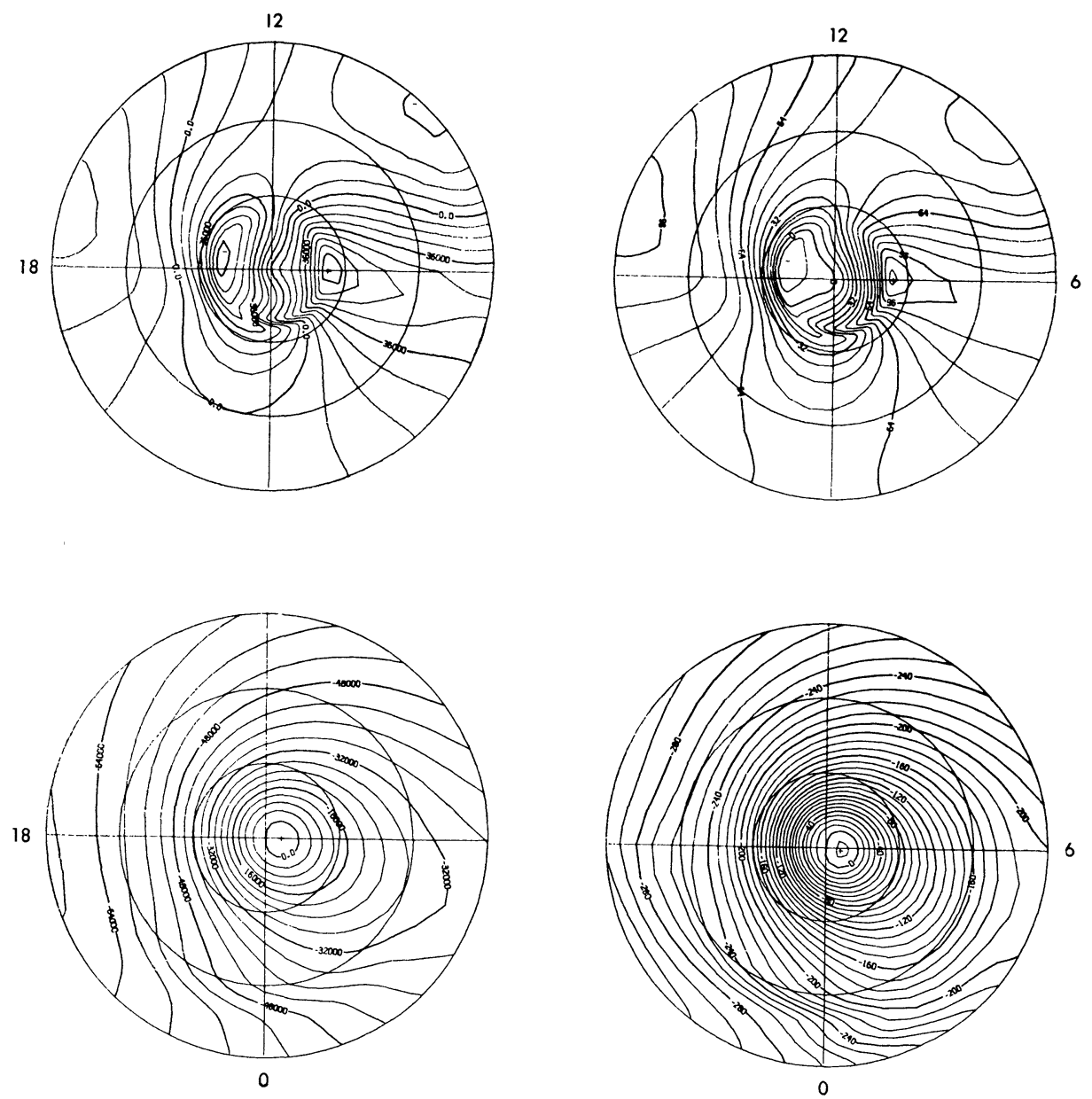

Fig. 5. Computer simulated equivalent overhead current systems on toward (top left) and away (top right) summer quiet days, and circular currents obtained from the difference between toward and away (hence twice as large as toward or away minus all-average) on summer quiet (bottom left) and disturbed (bottom right) days with a contour interval of approximately $10^{4}$ amp for quiet and $2 \times 10^{4}$ amp for disturbed days.

tric currents in the lower thermosphere over the polar region produced by the IMF azimuthal component.

\section{Concluding Remarks}

The relations between the IMF and lower thermospheric dynamics and electric currents are briefly reviewed in the present report. There seem to be two types of correlations between the two phenomena:

1) Indirect correlation: Magnetospheric disturbances caused by the southward IMF (which lasts longer than three hours) or by sector boundary passages may produce storm-related thermospheric motions and currents; and 
2) Direct correlation: The IMF azimuthal component produces circular electric currents in the lower thermosphere over the polar region. (However, special current systems, such as DP2, DP3, etc., which have been suggested as being produced by the IMF north-south component, $\pm B_{z}$, need to be reexamined in order to establish consistent current patterns.)

IMFP effects on quiet geomagnetic fields in middle and low latitudes are caused by changed magnetospheric configurations, and hence there is probably no noticeable change of the lower thermosphere during quiet periods. However, it is likely that some effects occur in middle latitudes originating from high latitudes due to the IMFP, which need to be examined in the future. Another remaining problem is to find IMFP effects on middle and low latitude fields during disturbed periods. In any case, it is interesting to know that a small amount (several gammas) of IMF can trigger a large effect in the lower thermosphere.

The author is very grateful to Drs. Y. Kamide and A.D. Richmond for their extremely helpful discussions. The National Center for Atmospheric Research is sponsored by the National Science Foundation.

\section{REFERENCES}

Arthur, C.W. and R.L. MCPherron, Interplanetary magnetic field conditions associated with synchronous orbit observations of Pc 3 magnetic pulsations, J. Geophys. Res., 82, 5138-5142, 1977.

Atkinson, G., Equations for magnetospheric convection and a solution for polar cap flows, J. Geophys. Res., 80, 32-36, 1975.

Berthelier, A., Étude de l'effet de la composante Est-Ouest du champ magnétique interplanétaire sur les courants équivalents aux perturbations magnétiques des régions de haute latitude, C.R. Acad. Sci., Sér. B, 275, 841-844, 1972.

BERTHELIER, A., Influence of the polarity of the interplanetary magnetic field on the annual and the diurnal variations of magnetic activity, J. Geophys. Res., 81, 4546-4552, 1976.

BURCH, J.L., Observations of interactions between interplanetary and geomagnetic fields, Rev. Geophys. Space Phys., 12, 363-378, 1974.

CAmpbell, W.H., Polar cap geomagnetic field responses to solar sector changes, J. Geophys. Res., 81, 4731-4744, 1976.

CAmpbell, W.H. and S. Matsushita, Correspondence of solar field sector direction and polar cap geomagnetic field changes for 1965, J. Geophys. Res., 78, 2079-2087, 1973.

COMFort, R.H., S.T. Wu, and G.R. Swenson, An analysis of auroral $E$ region neutral winds based on incoherent scatter radar observations at Chatanika, Planet. Space Sci., 24, 541-560, 1976.

ELY, J.T.A., Equatorial modulation and north-south asymmetry of galactic cosmic rays due to the interplanetary magnetic field, J. Geophys. Res., 82, 3643-3648, 1977.

FAIRFIELD, D.H., Electric and magnetic fields in the high-latitude magnetosphere, Rev. Geophys. Space Phys., 15, 285-298, 1977.

Feldstein, Ya. I., Magnetic field variations in the polar region during magnetically quiet periods and interplanetary magnetic fields, Space Sci. Rev., 18, 777-861, 1976.

Fris-Christensen, E. and J. Wilhjelm, Polar cap currents for different directions of the interplanetary magnetic field in the $Y-Z$ plane, J. Geophys. Res., 80, 1248-1260, 1975.

Gosling, J.T., J.R. Asbridge, S.J. BAme, and W.C. Feldman, Solar wind speed variations: 19621974, J. Geophys. Res., 81, 5061-5070, 1976.

HEPPNER, J.P., Polar-cap electric field distributions related to the interplanetary magnetic field direction, J. Geophys. Res., 77, 4877-4887, 1972. 
HePpNer, J.P., High latitude electric fields and the modulations related to interplanetary magnetic field parameters, Radio Sci., 8, 933-948, 1973.

IWASAKI, N., Localized abnormal geomagnetic disturbances near the geomagnetic pole and simultaneous ionospheric variation, Rep. Ionosph. Space Res. Japan, 25, 163-186, 1971.

Jørgensen, T.S., E. FriIs-Christensen, and J. Wilhjelm, Interplanetary magnetic-field direction and high-latitude ionospheric currents, J. Geophys. Res., 77, 1976-1977, 1972.

Kamide, Y. and S. Matsushita, A unified view of substorm sequences, J. Geophys. Res., 83, 21032108, 1978.

Kamide, Y. and S. Matsushita, Simulation studies of ionospheric electric fields and currents in relation to field-aligned currents (1. Quiet periods; 2. Substorms), J. Geophys. Res., 84, 1979 (in press).

Kuznetsov, B.M. and O.A. Troshichev, On the nature of polar cap magnetic activity during undisturbed periods, Planet. Space Sci., 25, 15-21, 1977.

Larsen, M.F. and M.C. Kelley, A study of an observed and forecasted meteorological index and its relation to the interplanetary magnetic field, Geophys. Res. Letters, 4, 337-340, 1977.

LOCKWOOD, J.A. and W.R. WEBBER, Forbush decreases and interplanetary magnetic field disturbances, J. Geophys. Res., 82, 1906-1914, 1977.

Maezawa, K., Magnetospheric convection induced by the positive and negative $Z$ components of the interplanetary magnetic field: Quantitative analysis using polar cap magnetic records, $J$. Geophys. Res., 81, 2289-2303, 1976.

Matsushita, S., Morphology of slowly-varying geomagnetic external fields-A review, Phys. Earth Planet. Interiors, 10, 299-312, 1975a.

Matsushita, S., IMF polarity effects on the $S q$ current focus location, J. Geophys. Res., 80, 47514754, $1975 b$.

MAtsushitA, S., IMFP effects on the equatorial geomagnetic field and ionosphere-A review, $J$. Atmos. Terr. Phys., 39, 1207-1215, 1977.

Matsushita, S. and B.B. Balsley, A question of DP-2, Planet. Space Sci., 20, 1259-1267, 1972.

Matsushita, S. and B.B. BAlsley, Comments on Nishida's reply, Planet. Space Sci., 21, 1260-1262, 1973.

Matsushita, S. and Y. KAmide, IMFP effects on the polar geomagnetic field, Planet. Space Sci., 28, 1980 (in press).

Matsushita, S., J.D. TARPLey, and W.H. CAMPBell, IMF sector structure effects on the quiet geomagnetic field, Radio Sci., 8, 963-972, 1973.

NishidA, A., Coherence of geomagnetic DP-2 fluctuations with interplanetary magnetic variations, J. Geophys. Res., 73, 5549-5559, 1968.

Nishida, A., Interplanetary field effect on the magnetosphere, Space Sci. Rev., 17, 353-389, 1975.

RANGARAJAN, G.K., Response of low latitude geomagnetic activity to sector boundary passage, Planet. Space Sci., 25, 465-471, 1977.

RAO, D.R.K. and B.R. ARORA, Modulation of geomagnetic lunar variation by the sector polarity of IMF, J. Geomag. Geoelectr., 29, 137-142, 1977.

REITER, R., The electric potential of the ionosphere as controlled by the solar magnetic sector structure. Result of a study over the period of a solar cycle, J. Atmos. Terr. Phys., 39, 95-99, 1977.

Richmond, A.D. and S. Matsushita, Thermospheric response to a magnetic substorm, J. Geophys. Res., 80, 2839-2850, 1975.

Rishbeth, H., F-region storms and thermospheric circulation, J. Atmos. Terr. Phys., 37, 1055-1064, 1975.

Roble, R.G. and M.H. Rees, Time-dependent studies of the aurora: Effects of particle precipitation on the dynamic morphology of ionospheric and atmospheric properties, Planet. Space Sci., 25, 991-1010, 1977.

Russell, C.T. and B.K. Fleming, Magnetic pulsations as a probe of the interplanetary magnetic field: A test of the Borok B index, J. Geophys. Res., 81, 5882-5886, 1976.

Russell, C.T. and R.L. MCPherron, Semiannual variation of geomagnetic activity, J. Geophys. Res., 78, 92-108, 1973.

SCHLegel, K., G. Rose, and H.U. Widdel, Interplanetary magnetic field polarity changes and $D$ region radio wave absorption, J. Atmos. Terr. Phys., 39, 101-103, 1977. 
SvalgaARD, L., Interplanetary magnetic-sector structure 1926-1971, J. Geophys. Res., 77, 4027-4034, 1972.

SVAlgaArd, L., Polar cap magnetic variations and their relationship with the interplanetary magnetic sector structure, J. Geophys. Res., 78, 2064-2078, 1973.

SvalgaARD, L., Recalibration of Bartels' geomagnetic activity indices $K p$ and $a p$ to include universal time variations, J. Geophys. Res., 81, 5182-5188, 1976.

Testud, J., P. Amayenc, and M. Blanc, Middle and low latitude effects of auroral disturbances from incoherent-scatter, J. Atmos. Terr. Phys., 37, 989-1009, 1975.

Volland, H., Differential rotation of the magnetospheric plasma as cause of the Svalgaard-Mansurov effect, J. Geophys. Res., 80, 2311-2315, 1975a.

Volland, H., Models of global electric fields within the magnetosphere, Ann. Géophys., 31, 159-173, 1975 b.

WeBb, D. and D. ORR, Geomagnetic pulsations $(5-50 \mathrm{mHz})$ and the interplanetary magnetic field, $J$. Geophys. Res., 81, 5941-5947, 1976.

Wilcox, J.M., A synoptic approach to sun-weather investigations, J. Atmos. Terr. Phys., 39, 173-178, 1977.

WiLcox, J.M. and N.F. Ness, Quasi-stationary corotating structure in the interplanetary medium, J. Geophys. Res., 70, 5793-5805, 1965.

WinkLeR, C.N. and P.J. Bedisn, Long-term cosmic ray modulation in the period 1966-1972 and interplanetary magnetic fields, J. Geophys. Res., 81, 3198-3206, 1976. 